\title{
Non-luminescent nature of the planar deformation features in shocked quartz from the Ries impact structure, Germany: A new interpretation
}

\author{
Arnold Gucsik ${ }^{1,2 *}$, Tasuku Okumura ${ }^{3}$, Hirotsugu Nishido ${ }^{4}$, Ildikó Gyollai, \\ Kiyotaka Ninagawa ${ }^{6}$, Natalie Deseta ${ }^{7}$, Péter Rózsa ${ }^{8}$
}

\author{
${ }^{1}$ Department of Geology, University of Johannesburg, Johannesburg, South Africa \\ ${ }^{2}$ Konkoly Observatory, Hungarian Academy of Sciences, Budapest, Hungary \\ ${ }^{3}$ Isotope MS Field Team, Field Support Department, Thermo Fisher Scientific K.K., Yokohama, Japan \\ ${ }^{4}$ Department of Biosphere-Geosphere Science, Okayama University of Science, Okayama, Japan \\ ${ }^{5}$ Department of Lithospheric Research, University of Vienna, Vienna, Austria \\ ${ }^{6}$ Department of Applied Physics, Okayama University of Science, Okayama, Japan \\ ${ }^{7}$ Planetary and Space Science Center, University of New Brunswick, Fredericton, Canada \\ ${ }^{8}$ Department of Mineralogy, University of Debrecen, Debrecen, Hungary
}

Received: March 29, 2014; accepted: March 5, 2015

Quartz grains from the Ries impact structure containing shock-induced microstructures were investigated using Scanning Electron Microscopy in cathodoluminescence (SEM-CL), secondary electron (SEM-SE) and back-scattered electron (SEM-BSE) modes as well as Mott-Seitz analysis. The purpose of this study is to evaluate the mechanism by which CL detects Planar Deformation Features (PDFs) in quartz, which is one of the most important indicators of shock metamorphism in rock-forming minerals. PDFs are micron-scale features not easily identified using optical microscopy or scanning electron microscopy. The CL spectrum of PDFs in quartz that has suffered relatively high shock pressure shows no or a relatively weak emission band at around $385 \mathrm{~nm}$, whereas an emission band with a maximum near $650 \mathrm{~nm}$ is observed independent of shock pressure. Thus, the $\sim 385 \mathrm{~nm}$ intensity in shocked quartz demonstrates a tendency to decrease with increasing shock metamorphic stage, whereas the $650 \mathrm{~nm}$ band remains fairly constant. The result indicates that the emission band at $385 \mathrm{~nm}$ is related to the deformed structure of quartz as PDFs.

Keywords: planar deformation features, cathodoluminescence, shock waves, quartz, meteorite crater

\footnotetext{
* Corresponding author: Konkoly-Thege Miklós út 15-17, H-1121 Budapest, Hungary;

E-mail: gucsik@mailmax.hu
} 


\section{Introduction}

Planar Deformation Features (PDFs) of rock-forming minerals, especially in quartz, are one of the most important mineralogical indicators of shock metamorphism, which is considered evidence for the impact origin of certain geological structures (French and Short 1968; Stöffler 1974; Hörz 1982; Grieve 1987, 1991; Grieve et al. 1996; Koeberl 1997). PDFs are defined as sets of closely spaced $(<5 \mu \mathrm{m})$, narrow (1-3 $\mu \mathrm{m})$, parallel planar substructures occurring along certain crystallographic slip planes (Engelhardt and Bertsch 1969; John et al. 1993; French 1998; Langenhorst 2002; French and Koeberl 2010). The planar substructures typically contain amorphous or glassy material of the composition of the host mineral.

PDFs have already been investigated by transmission electron microscopy (TEM); however, these studies were unable to determine the formation mechanism of these structures (Goltrant et al. 1991, 1992; Leroux et al. 1994). The CL spectroscopic properties of shocked quartz, as well as its PDFs, have been described from various shock metamorphic environments such as terrestrial impact structures (e.g., Ramseyer et al. 1992; Dypvik et al. 1996; Seyedolali et al. 1997; Boggs et al. 2001; Trepmann et al. 2005; Götte 2009; Hamers and Drury 2011 and references therein) and shock recovery experiments (Gucsik et al. 2003). The question of whether shock metamorphic effects can modify the luminescent nature of quartz under high pressure was first addressed in a pioneering study by Boggs et al. (2001). However, these authors were not able to explain the CL behavior of PDFs, in particular, their non-radiative character shown in the CL images. More recently, the shock-induced amorphization in PDFs of quartz samples from the Ries impact structure (at the Polsingen sampling site) was analyzed by micro-Raman spectroscopy (Gucsik et al. 2011). They found that Raman intensity exhibits a moderate increase in the range of 230 to $450 \mathrm{~cm}^{-1}$ indicating that PDFs are in-filled by an amorphous phase. They concluded that the $\mathrm{SiO}_{4}$ tetrahedral cluster-type structure is generated along the breaking of $\mathrm{Si}-\mathrm{O}-\mathrm{Si}$ bonds in the quartz structure by shock pressure (Gucsik et al. 2011 and references therein).

The luminescence properties of shocked quartz and its shock-induced microstructures both in natural and experimental cases are poorly understood (e.g., Ramseyer et al. 1992; Dypvik et al. 1996; Seyedolali et al. 1997; Boggs et al. 2001; Gucsik et al. 2003, 2004; Trepmann et al. 2005; Götte 2009; Okumura et al. 2009; Hamers and Drury 2011 and references therein). In this study our primary aim was to explain the CL behavior of shocked quartz, including the origin and characteristics of the CL signal in PDFs. These results not only contribute to an improved understanding of the formation conditions of PDFs in quartz (e.g. during a meteorite impact), but also reveal the potential for shock-induced effects, such as new electronic transitions in shocked quartz samples.

The strengths of SEM-CL in this study are that it allows high resolution imaging of defects and changes in recombination centers in materials such as PDFs, which optical microscopy and SEM-BSE cannot achieve. Further, by exploring the mechanism that separates SEM-CL from the other spectroscopic methods, BSE in particu- 
lar, we can make inferences about the physico-chemical nature of PDFs. SEM-BSE imaging is an important tool in petrology as it is able to identify phases based on their atomic numbers, facilitating the identification of minerals, mineral zoning and intergrowths. However, SEM-BSE cannot discern the degree of crystallinity, recombination or polymerization of a sample. It cannot tell you whether you are looking at a glass or a crystalline phase, except by texture, as they appear the same under SEM-BSE. SEM-CL imaging is an optical method that exploits the phenomenon of electron excitation in the visible spectrum using a high energy electron beam. The resultant emissions arise from defects in the crystal lattice. CL presents petrologists interested in deformation structures and mechanisms at the micro-scale with a method to analyze minerals based on the nature and distribution of their defects. CL-SEM defect mapping could be a potentially more user-friendly method of mapping than complex numerical modeling. Furthermore, the two methods could be used in conjunction with each other for corroboration.

\section{Samples and experimental procedure}

\section{Samples}

The Ries impact structure (26 km in diameter, $15 \mathrm{Ma}$ ), a complex meteorite impact crater located in Southern Germany ( $48^{\circ} 53^{\prime}$, E $10^{\circ} 37^{\prime}$ ), provides some of the best-preserved samples to illustrate the formation conditions of terrestrial impact cratering and its geologic as well as geochemical consequences (Staudacher et al. 1982; Engelhardt 1990; Deutsch 1998; Stöffler and Grieve 2007).

In this study, quartz samples with well-developed sets of planar microstructures (PFs and PDFs) were selected from a total of 16 thin sections from two sampling sites: (1) suevite from Seelbronn (which is situated near Amerdingen, about $20 \mathrm{~km} \mathrm{SSW}$ of Nördlingen) and (2) impact rock containing a cemented matrix from Polsingen (which is located about $20 \mathrm{~km}$ NNE of Nördlingen), Ries crater, Germany (Fig. 1). Both quarries contain impact breccia, suevite and highly shocked biotite and plagioclase, which fall into the shock stage ranging between 15-25 GPa. Well-developed multiple sets of PDFs coexisting with Planar Fractures (PFs) were observed in the shocked quartz grains from the above-mentioned sampling sites.

\section{Methodology}

CL imaging and spectral analyses (secondary electron and back-scattered electron imaging) were performed using Scanning Electron Microscope cathodoluminescence (SEM-CL), on an SEM (JEOL JSM-5410LV) (Oxford Mono CL2) at Okayama University of Science, Okayama, Japan. The system configuration has been described in detail in Okumura et al. (2006) and Kayama et al. (2010). Operating conditions for all SEM-CL images and spectroscopy as well as SE imaging 


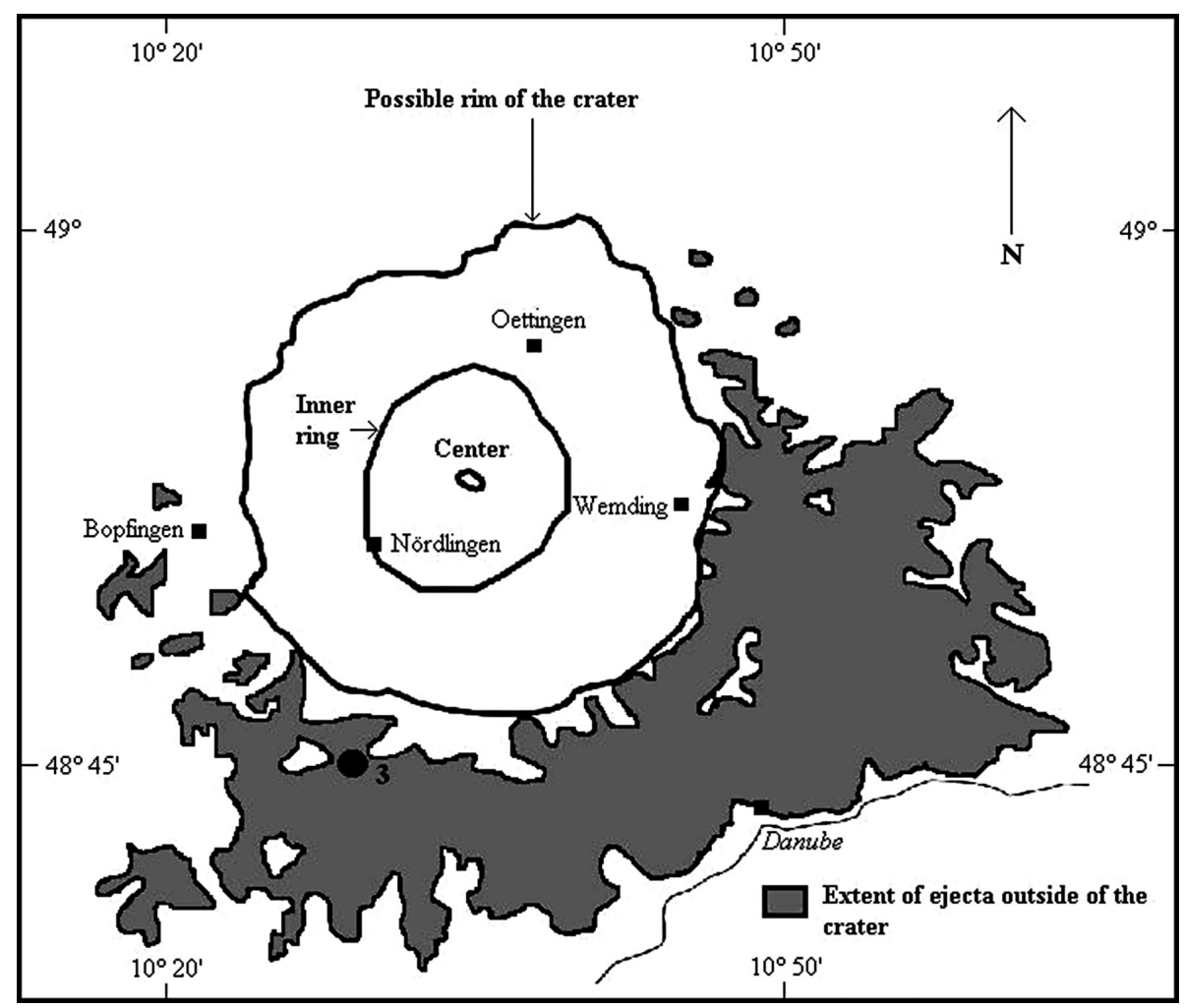

Fig. 1

Locality of the Ries basin in Germany. Sample localities are indicated as follows; 1 = Polsingen, 2 = Seelbronn (based on the 1:50 000 map of the Bayerisches Geologisches Landesamt) (Geologische Karte des Rieses, 1999). The diameter of the crater is approximately $26 \mathrm{~km}$

were $15 \mathrm{kV}$ accelerating voltage and beam current $2.0 \mathrm{nA}$ at room temperature. $\mathrm{CL}$ spectra were recorded between $350-850 \mathrm{~nm}$, with $1 \mathrm{~nm}$ resolution, using the photon counting method and a photomultiplier (PMT) detector, Hamamatsu Photonics R2228. The CL spectral data were acquired as a function of wavelength (nm), and were corrected for calibration. SEM-CL studies used polished thin sections, with the sections being prepared using a non-luminescent epoxy material (Devcon ET, ITW Industries, Co. LTD., Japan) and coated with a $20 \mathrm{~nm}$ thickness of carbon in order to avoid charge build-up. The final polishing was done using colloidal silica. An un-shocked quartz sample from Minas Gerais was used for testing acquisition time of the spectra to determine whether CL spectral properties of quartz are affected by CL-irradiation. 


\section{Results}

\section{Scanning Electron Microscope cathodoluminescence (SEM-CL) observations}

A selection of representative grains (from 36 grains in total) for optical, secondary electron (SE) and SEM-CL imaging, as well as CL spectral measurements of shocked quartz grains were obtained in a suevite (an impact breccia) from Seelbronn. The planar microstructures of quartz grains observed show roughly straight cracks using optical microscopy (Fig. 2a) and SEM-SE (Fig. 2b) images. In SEM-CL images (Fig. 2c), well-developed PDFs are observed occurring as dark parallel sets with $<1 \mu \mathrm{m}$ width and spacing 1 5 $\mu \mathrm{m}$. Compared to the SEM-SE and optical micrographs, the SEM-CL image shows PDFs in significantly more detail (Fig. 2c).

(a)

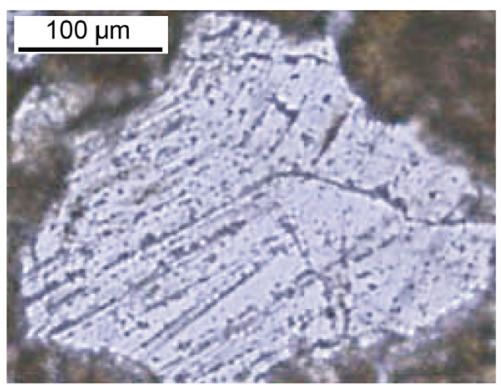

(c)

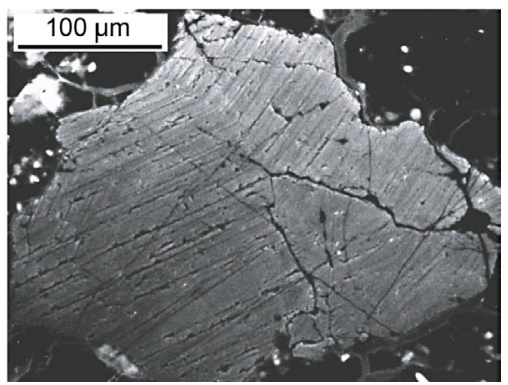

(b)

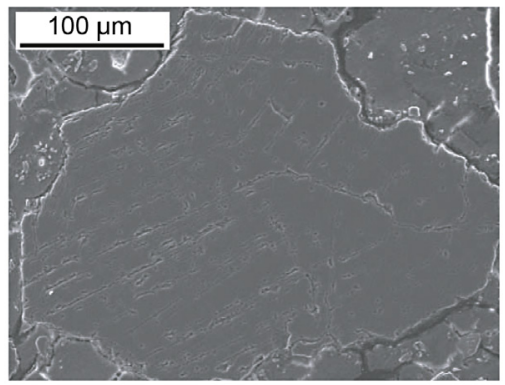

Fig. 2

Optical micrographs under transmitted light with open nicols (a), Secondary Electron Image (b) and Scanning Electron Microscope cathodoluminescence image (c) of a shocked quartz grain with Planar Deformation Features (PDFs) in suevite from Seelbronn

\section{Cathodoluminescence spectroscopy}

CL spectra of PDFs from both sampling sites are dominated by an emission band centered at $\sim 385 \mathrm{~nm}$ (near UV) and a broad band at $\sim 650 \mathrm{~nm}$ (red region) (Fig. 3a and $b$ ). The CL emission intensities at $385 \mathrm{~nm}$ differ significantly in the shocked quartz grains, where the peak intensities of PDFs are lower by $25 \%$ than those in the crystalline phase. In contrast, CL spectroscopy shows almost no difference of the emission intensities at $650 \mathrm{~nm}$ between PDFs and host in the shocked quartz grains (Fig. 3a and b). 
a)

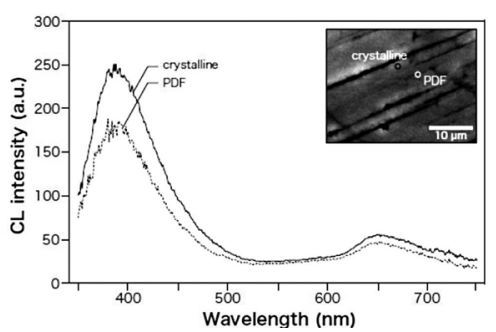

b)

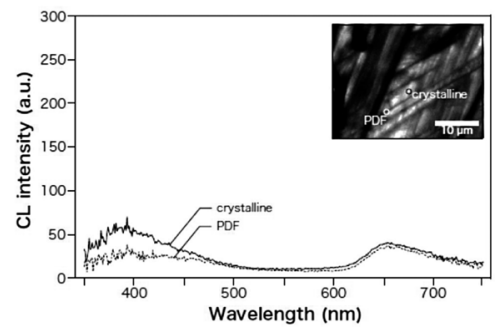

Fig. 3

CL spectra from a Planar Deformation Feature (PDF) and the host (crystalline) part of shocked quartz grains from Seelbronn (a) and Polsingen (b). CL spectra obtained from spots on PDF and crystalline host in inset SEM-CL images, which were taken at low temperature (less than $400{ }^{\circ} \mathrm{C}$ )

\section{Arrhenius plot of PDFs}

The probability of non-irradiative transitions depends on temperature and is represented as

$$
\mathrm{s} \exp (\varepsilon / \mathrm{kT})
$$

where $\mathrm{s}$ is frequency factor, $\mathrm{k}$ is Boltzmann constant, $\varepsilon$, the activation energy $(\mathrm{eV})$ for temperature quenching and $\mathrm{T}$ is absolute temperature $(\mathrm{K})$. The luminescence efficiency $(\eta)$ is then proportional to the probability of radiative, A, and that of non-radiative transitions and can be described as

$$
\eta=\mathrm{A} /[\mathrm{A}+\mathrm{s} \exp (\varepsilon / \mathrm{kT})] \text {. }
$$

To quantitatively evaluate the temperature dependence of CL intensity obtained by spectral measurements on room and liquid nitrogen temperatures (Fig. 4a), the activation energy for temperature quenching was estimated using equation (2) and assuming the Mott-Seitz model (Seitz 1939; Mott and Gurney 1948). This estimation is essential for conversion of CL spectra collected as a function of wavelength (nm)

a)



b)



Fig. 4

(a) CL spectra of unshocked and shocked quartz samples at various temperatures. (b) Compared to the shocked quartz samples, the unshocked quartz exhibits two temperature quenching processes ( $\mathrm{E}$ is 0.03 $\mathrm{eV}$ up to $-110^{\circ} \mathrm{C}$ and $0.235 \mathrm{eV}$ above $-110^{\circ} \mathrm{C}$ ) shown in the Arrhenius diagram 
into such in energy space (eV). It follows from equation (2) that in an Arrhenius plot of $\ln [(1 / \eta)-1]$ against $1 / \mathrm{T}$ as shown in Fig. $4 \mathrm{~b}$ the activation energy in temperature quenching processes can be estimated for each quartz sample from the slope of the least-square linear fit. Arrhenius plots are shown for two shocked quartz samples and lead to estimated activation energies of $\sim 0.072$ and $\sim 0.085 \mathrm{eV}$ in the temperature range from -180 to $-30^{\circ} \mathrm{C}$. In contrast to shocked quartz, which can be described by a single activation energy over the full temperature range, unshocked quartz shows evidence for two temperature quenching processes: $\varepsilon$ is $\sim 0.032 \mathrm{eV}$ below $-110{ }^{\circ} \mathrm{C}$ and $\sim 0.222 \mathrm{eV}$ above $-110{ }^{\circ} \mathrm{C}$ (Fig. 4b).

\section{Discussion}

\section{Broad emission bands at 385 and $650 \mathrm{~nm}$ in the shocked quartz}

The CL spectra of our shocked quartz samples are dominated by broad bands at $\sim 385$ and $650 \mathrm{~nm}$, which show an almost total absence of any sharp emission lines or the blue center $(380 \mathrm{~nm})$. The emission band at $\sim 385 \mathrm{~nm}$ in natural quartz has been associated with an aluminum (Al) impurity represented as $\left[\mathrm{AlO}_{4} / \mathrm{M}^{+}\right]^{0}$ $\left(\mathrm{M}^{+}: \mathrm{H}^{+}, \mathrm{Li}^{+}, \mathrm{Na}^{+}, \mathrm{K}^{+}\right.$) (Alonso et al. 1983; Itoh et al. 1988; Luff et al. 1990; Perny et al. 1992; Stevens-Kalceff et al. 2000; Götze et al. 2001). Gorton et al. (1997) also confirmed a weak emission band at $390 \mathrm{~nm}$ in ultra-pure synthetic quartz $(<0.1 \mathrm{ppm}$ Al contents). According to Toyoda and Ikeya (1991), the amount of Al centers in $\alpha$-quartz, in their studies on thermal stabilities of paramagnetic defects in Electron Spin Resonance (ESR) measurements, remarkably decreases over the range of $\sim 200$ to $450{ }^{\circ} \mathrm{C}$, with the $\mathrm{Al}$ center disappearing at $450{ }^{\circ} \mathrm{C}$. It is important to note that $\mathrm{CL}$ spectroscopy and ESR detect different Al-centers, which are related and transformed into each other by irradiating and annealing due to heating (cf. e.g. Götte et al. 2011, and references therein). The weaker emission band at $385 \mathrm{~nm}$ in quartz grains from Polsingen suggests that these grains suffered relatively higher shock metamorphism than those from Seelbronn, which was further confirmed using micro-Raman spectroscopy (Gucsik et al. 2011). However, determining the shock stage in impactites is complicated, as the suevite is composed of various types of impact rocks which indicate heterogeneous shock metamorphic effects, such that the degree of shock recorded is different in each quartz grain in the rock. The quenching of the emission band at $\sim 385 \mathrm{~nm}$ might be due to several processes: the migration of monovalent ions (e.g. $\mathrm{H}^{+}, \mathrm{Li}^{+}, \mathrm{Na}^{+}, \mathrm{K}^{+}$) with an increase in temperature by shock metamorphism. The Al center might disappear due to the modification of energy levels accompanying amorphization, or the breakdown of the $\mathrm{SiO}_{4}$ tetrahedral structure by shock metamorphism (Boggs et al. 2001). Therefore, the emission band at $\sim 385 \mathrm{~nm}$ has potential for indicating the types of deformation affecting quartz in different shock ranges, in which no other crystallographic changes have been observed. However, the assignment of the broad emission band centered at $385 \mathrm{~nm}$ to a particular transition 
is difficult because of widespread distribution of possible processes over a range of $<350$ to $500 \mathrm{~nm}$.

The broad emission band at $650 \mathrm{~nm}$ in quartz appears in both the CL spectra of the PDFs and its crystalline host. For the emission band at $\sim 650 \mathrm{~nm}, \mathrm{CL}$ spectroscopy revealed no remarkable differences in the emission intensity between samples. According to Stevens-Kalceff et al. (2000) and Götze et al. (2001), the emission band at around 620-650 $\mathrm{nm}$ has generally been noticed in both synthetic and natural quartz samples, and in cryptocrystalline silica such as agate and $\mathrm{SiO}_{2}$ glass (amorphous silica). Stevens-Kalceff and Phillips (1995) indicated that this emission is attributed to either a non-bridging oxygen hole center (NBOHC) or a trapped-electron $\mathrm{Si}_{3}{ }^{-}$center in crystalline quartz. Sigel and Marrone (1981) suggested that an emission band centered at $\sim 650 \mathrm{~nm}$ in silica glass is associated with a defect in the $\mathrm{Si}-\mathrm{O}$ network involving non-bridging oxygen ions. Since the $\sim 650 \mathrm{~nm}$ feature is observed in both crystalline and defective parts of the quartz crystals, the luminescence center attributed to $650 \mathrm{~nm}$ emission is interpreted as intrinsic to $\mathrm{SiO}_{2}$ and possibly impervious to shock metamorphism.

\section{Non-radiative nature of PDFs in $C L$}

It was observed that the energy difference (a band gap or BG) between the top of the valence band (VB) and the bottom of the conduction band (CB) in quartz is $\sim 9 \mathrm{eV}$ (O'Reilly and Robertson 1983) (Fig. 5a). Thus, even a small amount of energy from the electron beam will cause electrons to enter the $\mathrm{CB}$, from where they then fall back and move randomly through the crystal structure until they encounter a trap or recombination center existing between the VB and CB (Hayward 1998). Photon emission in the visible light range of the electromagnetic spectrum is produced by electrons that return to lower energy states via traps. However, light emission in the $\mathrm{UV}$ region of the spectrum is based on a direct return from the CB to the VB (Yacobi and Holt 1990; Gaft et al. 2005). According to Boggs et al. (2001) and Nasdala et al. (2003), quartz is an insulator mineral, in which the band gap between CB and VB is too large for thermal (at relatively low temperatures) excitation to promote electrons from lower-energy states to the higher-energy states.

These paths in the visible range are schematically illustrated in an idealized crystal structure in Fig. 5a. A band gap (BG) exists between VB and CB. As discussed below, the shock-induced amorphization initiates electronic transition processes in defect centers (e.g., by breaking $\mathrm{Si}-\mathrm{O}$ bonds and destroying the symmetry by shifting of the atoms from the lattice sites), which are correlated to the $350 \mathrm{~nm} \mathrm{CL}$ emission. The amorphous infilling of the PDFs modifies the energy level arrangement of electron traps existing in the $\mathrm{BG}$, such that the luminescence process observed in the near-ultraviolet to blue range does not operate or is very ineffective. This means that the amorphous material causes new closely-spaced energy levels due to its disordered nature, which indicates the electrons can easily return to their initial state with the emission of low-energy photons, or by losing energy to the lattice in the 
(a)

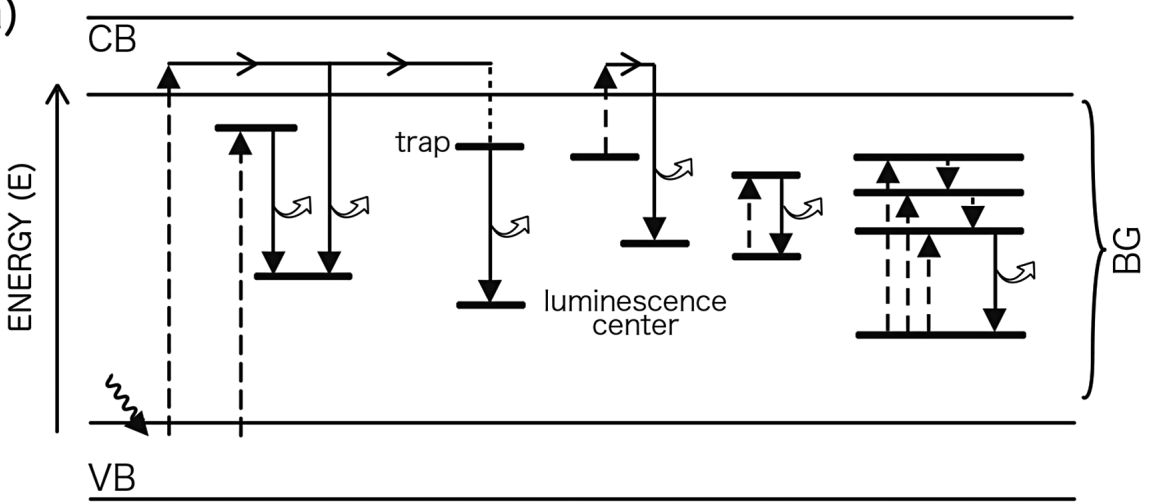

(b)

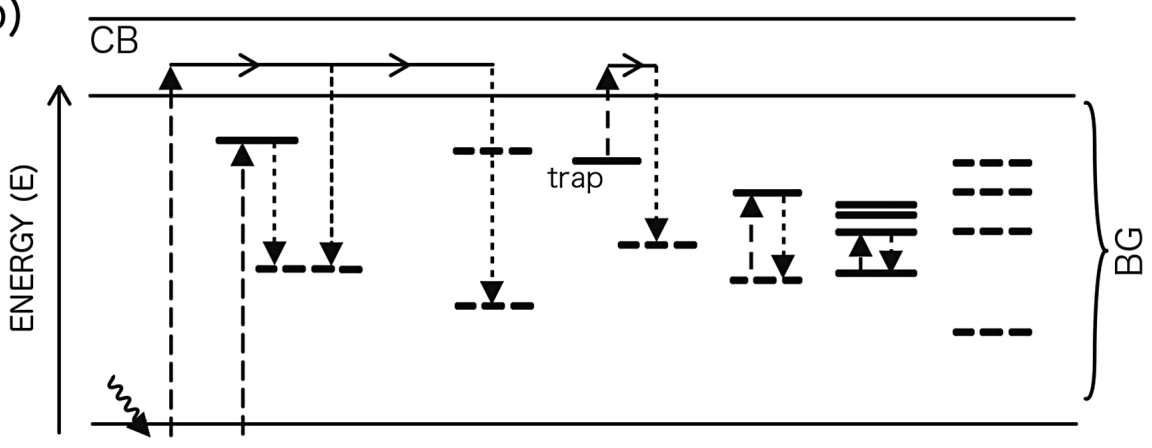

VB

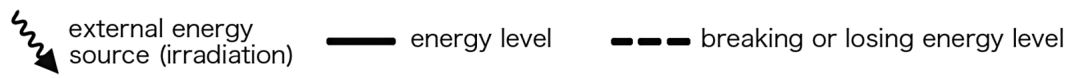

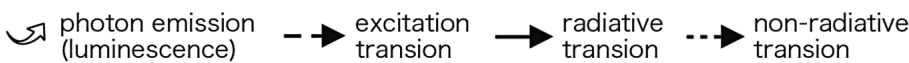

Fig. 5

(a) Simplified energy diagram of luminescence generated by electron irradition in the visible range (modified after Nasdala et al. 2003). VB and CB are valence and conduction bands, respectively. (b) Shock-induced amorphization of PDFs can cause closely-spaced electron trap/recombination centers leading to non-radiative transitions in the band gap (BG) of quartz

form of heat (phonon emission) (Fig. 5b). These results may corroborate the observations of Boggs et al. (2001) and agree with the conclusions obtained from our Raman spectroscopic observations (Gucsik et al. 2011). Alternatively, the non-luminescent nature of PDFs may be due to the absence of traps or recombination centers because of amorphization. 


\section{Conclusions}

Cathodoluminescence (CL) microscopy on PDFs in shocked quartz grains from the Ries impact crater, Germany, shows these features as dark lines (no visible light emitted). The CL spectra of these samples exhibit broad bands at $\sim 385 \mathrm{~nm}$ in the near-ultraviolet to blue range, and at $\sim 650 \mathrm{~nm}$ in the red range, which might be associated with $\mathrm{Al}$ centers and a non-bridging oxygen hole center (NBOHC), respectively. This indicates that recombination centers or traps for photon emission are more closely-spaced within the BG (Fig. 4), which is probably caused by the partial amorphization of the quartz and/or an instantaneous increase in temperature up to $500{ }^{\circ} \mathrm{C}$. Thus, the intensity of the emission band at $385 \mathrm{~nm}$ has potential as a shock indicator of shock in quartz.

Concerning the CL spectral features as well as Mott-Seitz analysis, we conclude that the phase transformation of quartz leads to small symmetry and electronic structure-breaking displacements of atoms resulting in non-radiative processes in the luminescence emission. We note that the CL technique employed here is a useful and powerful tool for the identification of shock-induced micro-deformation in rock-forming minerals. We have interpreted the lack of emission in PDFs in shocked quartz as a lack of recombination of monovalent ions and/or Al centers within the $\mathrm{SiO}_{4}$ lattice structure. This is in agreement with the high degree of disorder in the amorphous materials as detected by micro-Raman spectroscopy. SEM-BSE imaging shows no compositional zoning at the boundaries between PDFs and the quartz host, nor evidence of any nucleation or growth of new product phase indicating the glassy infilling of the PDFs is truly amorphous. However, quartz high-pressure polymorphs, stishovite and coesite, also appear dark under SEM-CL, but these minerals have distinct Raman spectra, ruling out the likelihood of a polymorphic phase transformation. Future detailed analysis using SEM-CL on PDFs, stishovite and coesite are planned. Structurally, the PDFs are brittle fractures along crystallographic planes, containing an infilling of amorphous material involving a syndeformational shear component. These features combined with the lack of Al and/or monovalent recombination indicate the dominance of combined or competing pressure or strain rate control on PDF formation via disequilibrium martensitic transformation of the shocked quartz, rather than displacive or reconstructive mineral transformations (Sharp and de Carli 2006). The observations and inferences from this study show that SEM-CL, combined with other compositional and spectroscopic data, may prove a fundamental tool in analyzing and mapping physico-chemical microscale defect distributions and deformation processes of interest to materials, engineering and earth scientists. 


\section{Acknowledgements}

A.G. acknowledges support from the Max Planck Institute for Chemistry, Mainz, Germany and the NRF Free-standing Postdoctoral Fellowship at the University of Johannesburg, South Africa. We thank Dr. Ulrich Ott at the Department of Geochemistry (Max Planck Institute for Chemistry, Mainz, Germany), Dr. Chitaro Gouzu (Hiruzen Institute for Geology and Chronology, Okayama, Japan), Dr. Yorinao Shitaoka (Kanazawa University, Ishikawa, Japan) and Prof. Michael Gaft (Laser Distance Spectrometry Ltd., Israel) for their useful comments on this manuscript.

\section{References}

Alonso, P.J., L.E. Halliburton, E.E. Kohnke, R.B. Bossoli 1983: X-ray induced luminescence in crystalline $\mathrm{SiO}_{2}$.- Journal of Applied Physics, 54, pp. 5369-5375.

Boggs, S., D.H. Krinsley, G.G. Goles, A. Seydolali, H. Dypvik 2001: Identification of shocked quartz by scanning cathodoluminescence imaging. - Meteoritics and Planetary Science, 36, 783-793.

Deutsch, A. 1998: Examples for terrestrial impact structures. - In: Marfunin, A.S. (Ed.): Mineral matter in space, mantle, ocean floor, biosphere, environmental management, and jewelry. Advanced Mineralogy Series, 3, pp. 119-129.

Dypvik, H., S.T. Gudlaugsson, M. Tsikalas, M.Jr. Attrep, R.E.Jr. Ferrell, D.H. Krinsley, A. Mørk, J.I. Faleide, J. Nagy 1996: Mjølnir structure: An impact crater in the Barents Sea. - Geology, 24, pp. 779-782.

Engelhardt, W.v. 1990. Distribution, petrography and shock metamorphism of the ejecta of the Ries crater in Germany - a review. - Tectonophysics, 171, pp. 259-273.

Engelhardt, W.v., W. Bertsch 1969: Shock induced planar deformation structures in quartz from the Ries crater, Germany. - Contribution to Mineralogy and Petrology, 20, pp. 203-234.

French, B.M., 1998: Traces of Catastrophe: A Handbook of Shock-Metamorphic Effects in Terrestrial Meteorite Impact Structures. - LPI Contribution, 954, Lunar and Planetary Institute, Houston, 120 p.

French, B.M., N.M. Short (Eds) 1968: Shock Metamorphism of Natural Materials. - Mono Book Corporation, Baltimore, 644 p.

French, B.M., C. Koeberl, C. 2010: The convincing identification of terrestrial meteorite impact structures: What works, what doesn't, and why. - Earth Science Reviews, 98, pp. 123-170.

Gaft, M., R. Reisfeld, G. Panczer 2005: Luminescence Spectroscopy of Minerals and Materials. Springer-Verlag, Berlin, Heidelberg, 356 p.

Goltrant, O., P. Cordier, J.C. Doukhan 1991: Planar deformation features in shocked quartz: a transmission electron microscopy investigation. - Earth and Planetary Science Letters, 106, pp. 103-115.

Goltrant, O., H. Leroux, J.C. Doukhan, P. Cordier 1992: Formation mechanism of planar deformation features in naturally shocked quartz. - Physics of the Earth Planetary Interiors, 74, pp. 219-240.

Gorton, N.T., G. Walker, S.D. Burley 1997: Experimental analysis of the composite blue cathodoluminescence emission in quartz. - Journal of Luminescence, 72-74, pp. 669-671.

Götte, Th. 2009: Petrological modifications in continental target rocks from terrestrial impact structures: Evidence from cathodoluminescence:-In Gucsik, A. (Ed.): Cathodoluminescence and its Application in the Planetary Sciences, Springer, pp. 45-60.

Götte, Th., Th. Pettke, K. Ramseyer, M. Koch-Müller, J. Mullis 2011: Cathodoluminescence properties and trace element signature of hydrothermal quartz: A fingerprint of growth dynamics. Mineralogical Magazine, 96, pp. 802-813.

Götze, J., M. Plötze, D. Habermann 2001: Origin, spectral characteristics and practical applications of the cathodoluminescence (CL) of quartz - a review. - Mineralogy and Petrology, 71, pp. 225-250. 
Grieve, R.A.F. 1987: Terrestrial impact structures. - Annual Reviews of Earth and Planetary Science, 15, pp. $245-270$.

Grieve, R.A.F. 1991: Terrestrial impact: The record in the rocks. - Meteoritics, 26, pp. 175-194.

Grieve, R.A.F., F. Langenhorst, D. Stöffler 1996: Shock metamorphism of quartz in nature and experiment: II. Significance in geoscience. - Meteoritics and Planetary Science, 31, pp. 6-35.

Gucsik, A., C. Koeberl, F. Brandstätter, E. Libowitzky, W.U. Reimold 2003: Scanning electron microscopy, cathodoluminescence, and Raman spectroscopy of experimentally shock metamorphosed quartzite. - Meteoritics and Planetary Sciences, 38, pp. 1187-1197.

Gucsik, A., C. Koeberl, F. Brandstätter, E. Libowitzky, M. Zhang 2004: Infrared, Raman and cathodoluminescence studies of impact glasses. - Meteoritics and Planetary Science, 39, pp. 12731285 .

Gucsik, A., T. Okumura, M. Kayama, H. Nishido, K. Ninagawa 2011: Planar deformation features in quartz from the Ries impact crater: Advanced by Micro-Raman Spectroscopy. - Spectroscopy Letters, 44, pp. 469-473.

Hamers, M.F., M.R. Drury 2011: Scanning electron microscope-cathodoluminescence (SEM-CL) imaging of planar deformation features and tectonic deformation lamellae in quartz. - Meteoritics and Planetary Science, 46, pp. 1814-1831.

Hayward, C.L. 1998: Cathodoluminescence of ore and gangue minerals and its application in the minerals industry. - In: Cabri, L.J., D.J. Vaughan (Eds): Mineralogical Association of Canada Short Course Series, 27, pp. 269-325.

Hörz, F. 1982: Ejecta of the Ries crater, Germany. - In: Silver, L.T., P.H. Schultz (Eds): Geological Implications of Impacts of Large Asteroids and Comets on the Earth. Geological Society of America Special Paper, 190, pp. 39-55.

Itoh, C., K. Tanimura, N. Itoh 1988: Optical studies of self-trapped excitons in $\mathrm{SiO}_{2}$. - Journal of Physics C, 21, pp. 4693-4702.

John, B., J.B. Lyons, C.B. Officer, P.E. Borella, R. Lahodynsky 1993: Planar lammellar substructures in quartz. - Earth and Planetary Science Letters, 119, pp. 431-440.

Kayama, M., S. Nakano, H. Nishido 2010: Characteristics of emission centers in alkali feldspar: A new approach by using cathodoluminescence spectral deconvolution. - American Mineralogist, 95, pp. 1783-1795.

Koeberl, C. 1997: Impact cratering: the mineralogical and geochemical evidence. - In: Johnson, K.S., J.A. Campbell (Eds): Ames Structure in Northwest Oklahoma and Similar Features: Origin and Petroleum Production (1995 Symposium). Oklahoma Geological Survey Circular, 100, pp. 30-54.

Langenhorst, F. 2002: Shock metamorphism of some minerals: Basic introduction and microstructural observations. - Bulletin of Czech Geological Survey, 77, pp. 265-282.

Leroux, H., W.U. Reimold, J.C. Doukhan 1994: A T.E.M. investigation of shock metamorphism in quartz from the Vredefort dome, South Africa. - Tectonophysics, 230, pp. 223-239.

Luff, B.J., P.D. Townsend 1990: Cathodoluminescence of synthetic quartz. - Journal of Physics: Condensed Matter, 2, pp. 8089-8097.

Mott, N. F., R.W. Gurney 1948: Electronic Processes in Ionic Crystals. - Clarendon Press, Oxford, pp. 219-224.

Nasdala, L., M. Zhang, U. Kempe, G. Panczer, M. Gaft, M. Andrut, M. Plötze 2003: Spectroscopic methods applied to zircon. - In: Hanchar J.M., P.W.O. Hoskin (Eds): Zircon. Reviews of Mineralogy and Geochemistry, 53, pp. 427-467.

Okumura, T., H. Nishido, K. Ninagawa, T. Sakamoto 2006: Cathodoluminescence and Thermoluminescence Studies of Clay Minerals. - Clay Science, 13, pp. 59-68.

Okumura, T., A. Gucsik, H. Nishido, K. Ninagawa, S. Toyoda 2009: Cathodoluminescence microcharacterization of ballen silica in impactites. - AIP Proceedings of the International Conference, 1163, pp. 148-155.

O’Reilly, E.P., J. Robertson 1983: Theory of defects in vitreous silicon dioxide. - Physical Reviews, B27, pp. 3780-3795. 
Osinski, G.R. 2004: Impact melt rocks from the Ries impact structure, Germany: an origin as impact melt flows? - Earth and Planetary Science Letters, 226, pp. 529-543.

Perny, B., P. Eberhardt, K. Ramseyer, J. Mullis, R. Pankrath 1992: Microdistribution of A1, Li, and $\mathrm{Na}$ in a quartz: possible causes and correlation with short-lived cathodoluminescence. - American Mineralogist, 77, pp. 534-544.

Ramseyer, K., A.A. AlDahan, B. Collini, O. Landström 1992: Petrological modifications in granitic rocks from the Siljan impact structure: evidence from cathodoluminescence. - Tectonophyics, 216, pp. 195-204.

Seitz, F. 1939: An introduction of crystal luminescence. - Transactions of the Faraday Society, 35, pp. 74-85.

Seyedolali, A., D. Krinsley, S. Boggs, P.F. O’Hara, H. Dypvik, G.G. Goles 1997: Provenance interpretation of quartz by scanning electron microscope-cahtodoluminescence fabric analysis. - Geology, 25, pp. 787-790.

Sharp, T.G., P.S. de Carli 2006: Shock effects in meteorites. - In: Lauretta, D.S., Jr.H.Y. McSween (Eds): Meteorites and the Early Solar System II. University of Arizona Press, Tucson, pp. 653-677.

Sigel, G.H., M.J. Marrone 1981: Photoluminescence in as-drawn and irradiated silica optical fibers: An assessment of the role of non-bridging oxygen defect centers. - Journal of Non-Crystalline Solids, 45 , pp. 235-247.

Staudacher, T., K.E. Jessberger, B. Dominik, T. Kristen, A.O. Schaeffer 1982: 40Ar-39Ar of rocks and glasses from the Nördlinger Ries crater and the temperature history of impact breccias. - Journal of Geophysics, 51, pp. 1-11.

Stevens-Kalceff, M.A., M.R. Phillips 1995: Cathodoluminescence microcharacterization of the defect structure of quartz. - Physical Review B, 52, pp. 3122-3134.

Stevens-Kalceff, M.A., M.R. Phillips, A.R. Moon, W. Kalceff 2000: Cathodoluminescence microcharacterisation of silicon dioxide polymorphs. - In: Pagel, M., V. Barbin, Ph. Blanc, D. Ohnenstetter (Eds): Cathodoluminescence in Geosciences, Springer, Berlin, Heidelberg, New York, pp. 193-224.

Stöffler, D. 1974: Deformation and transformation of rock-forming minerals by natural and experimental shock processes. - Fortschritte Mineralogie, 49, pp. 256-298.

Stöffler, D., R.A.F. Grieve 2007: Impactites. - In: Fettes, D., J. Desmons (Eds): Metamorphic Rocks: A Classification and Glossary of Terms, Recommendations of the International Union of Geological Sciences, Cambridge University Press, Cambridge, 258 p.

Toyoda, S., M. Ikeya 1991: Thermal stabilities of paramagnetic defect and impurity centers in quartz: Basis for ESR dating of thermal history. - Geochemical Journal, 25, pp. 437-445.

Trepmann, C.A., T. Götte, J.G. Spray 2005: Impact-related Ca-metasomatism in crystalline target rocks from the Charlevoix structure, Canada. - Canadian Mineralogist, 43, pp. 553-567.

Yacobi, B., D. Holt 1990: Cathodoluminescence microscopy of inorganic solids. - Plenum Press, New York, 308 p. 